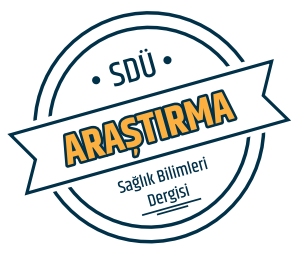

Sdü Sağlık Bilimleri Enstitüsü Dergisi / Cilt 8 Sayı 3 / 2017

\title{
Hemşirelik Öğrencilerinde Akıllı Telefon ve İnternet Bağımlılı̆̆ı ile Üst Ekstremite Fonksiyonel Aktivite Düzeyleri Arasındaki İlişkinin İncelenmesi
}

\author{
The Examination of Relationship between Smart Phone, Internet Addiction \\ and Upper Extremity Fuctional Activity Levels among Nursing Students
}

Dilek Yılmaz ${ }^{1}$, Hava Gökdere Çinar ${ }^{1}$, Nurcan Özyazıcıoğlü ${ }^{1}$

${ }^{1}$ Uludağ Üniversitesi Sağlık Bilimleri Fakültesi, Hemşirelik Bölümü, Bursa, Türkiye.

\begin{abstract}
Özet
Amaç: Bu araştırma hemşirelik öğrencilerinde akıllı telefon ve internet bağımlılığı ile üst ekstremite fonksiyonel aktivite düzeyleri arasındaki ilişkinin incelenmesi amacıyla yapıldı.

Materyal-Method: Tanımlayıcı ve kesitsel desende yürütülen araştırma, Türkiye'nin batı bölgesinde yer alan bir devlet üniversitesinin 2015-2016 öğretim yılında hemşirelik bölümünde öğrenim gören, araştırmanın yapıldığı dönemde ulaşılabilen ve araştırmaya katılmayı kabul eden 289 öğrenci ile gerçekleștirildi. Araştırma verilerinin toplanmasında; "Öğrenci Tanıtım Formu", "Akıllı Telefon Bağımlılığı Ölçeği-Kısa Formu (ATBÖ-KF)”, “İternet Bağımlılığı Ölçeği (İBÖ)" ve "Kol, Omuz ve El Sorunları Anketi (DASH)" kullanılmıştır. Verilerin değerlendirilmesi; sayı, yüzde, ortalama \pm standart sapma ile bağımsız $\mathrm{t}$ testi, tek yönlü varyans analizi (ANOVA) ve Pearson korelasyon analizi ile yapılmıştır.
\end{abstract}

Bulgular: Araştırmaya katılan öğrencilerin yaş ortalaması

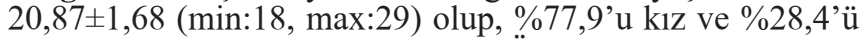
üçüncü sınıfta öğrenim görmektedir. Öğrencilerin \%45'i yurtta kaldığını, \%42,6'sı günde 40'dan fazla akıllı cep telefonunu kontrol ettiğini, \%49,5'i kendini akıllı telefon bağımlısı olarak değerlendirdiğini ifade etmiştir. Araştırmaya katılan

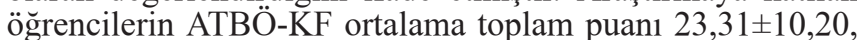
İBÖ ortalama toplam puanı $73,62 \pm 22,68$, DASH ortalama toplam puanı $42,97 \pm 12,18$ olarak belirlenmiștir. Yapılan istatistiksel analiz sonucunda; ATBÖ-KF ile İBÖ ve DASH arasında pozitif yönde anlamlı bir ilişki saptanmıştır $(\mathrm{p}<0,05)$. $\mathrm{K} 1 \mathrm{z}$ öğrencilerin DASH ortalama toplam puanı erkek öğrencilere göre anlamlı derecede yüksek olup $(p<0,05)$, cinsiyet faktörü ile İBÖ ve ATBÖ-KF toplam puanı arasında anlamlı bir fark olmadığı bulunmuştur ( $\mathrm{p}>0,05)$. Araştırmada öğrencilerin yaş, kaldıkları yer faktörlerinin akılll telefon ve internet bağımlık düzeylerini etkilemediği görülmüştür $(\mathrm{p}>0,05)$.

Sonuç: $\mathrm{Bu}$ çalıșma sonucunda, hemșirelik bölümü öğrencilerinin düşük düzeyde akıllı cep telefonu ve internet bağımlısı olduğu belirlenmiştir.

Anahtar kelimeler: Akıllı Telefon Bağımlılığı, İnternet Bağımlılığı, Üst Ekstremite Fonksiyonel Aktivite Düzeyi, Hemşirelik Öğrencileri

\begin{abstract}
Objective: This study was conducted in order to examine the relationship between smart phone, internet addiction and upper extremity functional activity levels of nursing students. Material-Method: Study which was conducted in definitive and sectional pattern, was carried out with 289 nursing student that continue education in 2015-2016 term and at a university which remain in the western part of Turkey and reachable during research and volunteered for the study. In the collection of study data; " Student Description Form", "Smart Phone Addiction Scale-Short Form" (SPAS-SF), "Internet Addiction Scale" (IAS), "The Disabilities of Arm, Shoulder and Hand" (DASH) were used. In the evaluation of data; number, percentage, average \pm standard deviation and Independent $t$ test, one way variance analysis (ANOVA) and Pearson correlation analysis were used.
\end{abstract}

Results: The average age of the students participating in the survey is $20,87 \pm 1,68$ ( $\min : 18, \max : 29), 77,9 \%$ are girls and $28,4 \%$ are in third grade. Forty-five percent of the students said they stayed in the dormitory, $42,6 \%$ said they control more their smartphones more than 40 times per day, and $49,5 \%$ rated themselves as smartphone addicts. The average SPAS-SF total score of the students who participated in the research was $23,31 \pm 10,20$, the mean total score of the IAS was $73,62 \pm 22,68$ and the DASH average total score was $42,97 \pm 12,18$. As a result of statistical analysis; there was a significant positive correlation between SPAS-SF, IAS and DASH $(p<0,05)$. The mean total DASH score of the female students was significantly higher than male students $(\mathrm{p}<0,05)$ and there was no significant difference between the gender factor and the IAS and SPAS-SF test scores $(p>0,05)$. Age, place of residence did not affect smart phone and internet dependency levels in the study.

Conclusions: In result of this study, it was found that nursing department students are smartphone and internet addicts in moderate level.

Keywords: Smartphone Addiction, Internet Addiction, Upper Extremity Functional Activity Level, Nursing Students. 


\section{Giriş}

Bağımlılık terimi, birmadde ya da davranıșı kullanmayı kontrol edememe veya bırakamama şeklinde tanımlanabilmektedir (1). Bağımlılık denince sadece sigara, alkol, uyuşturucu vb. madde bağımlılıkları akla gelmemeli, bunların dışında fiziksel bir maddeye dayanmayan, davranış tabanlı yeme bağımlılığı, oyun bağımlılığı, internet bağımlılığı, bilgisayar bağımlılı̆̆ı, alışveriş bağımlılı̆̆ 1 , televizyon bağımlılı̆̆ $\mathrm{gb}$. gibi bağımlılıkları da düşünülmelidir $(2,3)$.

Bağımlılık, genelde bireyin kendisi tarafından fark edilmeyebilmekte ve bu nedenle diğer rahatsılıklara oranla daha riskli durumlara dönüşebilmektedir. Birey çoğu zaman bağımlı olduğunun bilincinde olamamakta ve bu nedenle tedavi gereksinimi duymamaktadır. Bu nedenle bu problemin çözümü güç bir hal almaktadır (4).

Günümüzde teknolojik gelişmeler 1şığında bilgisayar, internet, cep telefonu ve son olarak da akıllı telefonlar günlük yaşamın vazgeçilmez parçaları durumuna gelmiştir. Özellikle akıllı telefonlar dünya çapında herkesin hayatının ayrılmaz bir parçası haline gelmiş olup insanlar cep telefonlarından kendilerini ayrılmaz hissetmektedirler (5). Amerika da yapılan bir çalışmada Amerikan 18-29 yaş aralığındaki gençlerin \%15 akıllı cep telefonlarına yoğun şekilde bağımlı oldukları bulunmuştur (6). Günüç ve Kayri (7), 754 öğrenciyle yürüttükleri bir çalışmada öğrencilerin \%10,1'nin internet bağımlısı olduğunu, Noyan ve arkadaşları (8) ise 367 öğrenciyle yaptıkları bir çalışmada ise öğrencilerin \%13,4'ünün kendilerini akıllı telefon bağımlısı olarak değerlendirdiklerini bildirmişlerdir.

Sadece iletişim kurmayı sağlayan cep telefonlarının yerini alarak kullanımı giderek artan akıllı telefonlar iletişim kurmanın yanı sıra özellikle internet erişimi, fotoğraf, müzik, video vb. paylaşımı firsatları sunma gibi avantajlara sahiptir $(8,9)$. Fakat akıllı telefon kullanımı günlük yaşamımıza birçok kolaylık getirmenin yanında kişilerarası ilişkiler, fiziksel ve ruhsal sağlık, kişilerin sağlığ 1 , mutluluğu ve genel işlevsellik üzerine etki ederek birçok olumsuz sonuca neden olabilmektedir (8,10-12). Yapılan bir çalışmada; akıllı telefon bağımlılığ 1 ile yalnızlık, çekingenlik duyguları arasında bir ilişki bulunmuştur (13). Ayrıca akıllı telefon ve internet bağımlılığı; gençlerin sosyal, akademik ve ev içi bazı problem yaşamasına neden olabileceği bildirilmiştir (14). Thomee ve arkadaşlarının (15) yapmış oldukları bir araştırma sonucunda da akıllı telefonların sürekli kullanımı kişilerde uyku rahatsızlıklarına, strese, kaygıya, fiziksel aktivitelerde azalma ve rahatsızlıklara yol açtığı saptanmıştır.

Diğer yandan akıllı telefon bağımlılığıyla paralel olarak internet bağımlılığı konusunda yapılan araştırmalar da özellikle son yıllarda artış göstermektedir. Buna en önemli neden olarak da internetin özellikle ergen ve gençler üzerinde bazı ciddi problemlere yol açan bir etken olarak gösterilebilmesidir (4). Yapılan çalışmalarda internet bağımlısı bireylerde depresyon durumu saptanmış ve depresyon hali ile internet bağımlılığı arasında güçlü bir ilişkinin olduğu belirtilmiştir (16-21). İnternet ve akıllı telefon kullanımındaki artış, psikososyal etkilerin yanı sıra kas iskelet sistemi sorunlarına da yol açabilmektedir. Bu sorunlar özellikle boyun, omuzlar, bilekler, eller ve dirsekler gibi üst ekstremitelerde görülebilmektedir (22).

Günümüz üniversite gençlerinde akıllı telefon ve internet bağımlılığının oluşturabileceği problemlerin toplumun bugününü ve yarınını tehdit etmesi nedeniyle, bu durumun incelenmesinin ve yol açtığ 1 problemlerin belirlenmesinin önem taşıdığ 1 düşünülmektedir. Konuyla ilgili literatürler incelendiğinde; ülkemizde gençlerde akıllı telefon ve internet bağımlılığının etkilerine yönelik sınırlı sayıda çalışmalara rastlanılmıştır $(7,8,11,16,18)$. Ayrıca çalışmalarda akıllı telefon ve internet bağımlılığının daha çok gençlerin akademik başarı düzeyine ve ruhsal sağlığına etkileri incelenmiş olup, üst ekstremite fonksiyonlarına yönelik etkisinin incelendiği hiçbir çalışma sonucuna rastlanılmamıştır $(7,8,16,18)$. Bu nedenle bu araştırmanın yapılmasına gerek duyulmuştur. Bu araştırma hemşirelik öğrencilerinde akıllı telefon ve internet bağımlılığ 1 ile üst ekstremite fonksiyonel aktivite düzeyleri arasındaki ilişkinin incelenmesi amacıyla yapılmıştır.

\section{Materyal-Method}

Bu araştırma prospektif, tanımlayıcı ve kesitsel tipte planlandı. Araştırmanın evrenini, Türkiye'nin batı bölgesinde yer alan bir devlet üniversitesinin 2015-2016 eğitim-öğretim yılında hemşirelik bölümünde öğrenim gören 520 öğrenci oluşturdu. Araştırmanın örneklemini ise akıllı telefon sahibi olan, araştırmanın yapıldığı dönemde ulaşılabilen ve araştırmaya katılmayı kabul eden 289 öğrenci oluşturdu (Araştırma evreni üzerinden katılım oran1: \%60,20).

Araştırmanın verileri, araştırmacılar tarafından geliştirilen öğrencilerin tanıtıcı özelliklerini içeren "Öğrenci Tanıtıcı Bilgi Formu", "Akıllı Telefon Bağımlılığı Ölçeği-Kısa Formu (ATBÖ-KF)", "İnternet Bağımlılığı Ölçeği (İBÖ)” ve "Kol, Omuz ve El Sorunları Anketi (DASH)" ile topland.

\section{Öğrenci Tanıtıcı Bilgi Formu}

Araştırmacılar tarafından geliştirilen bu formda, öğrencilerin yaş, sınıf, cinsiyet, kaldıkları yer, günlük olarak akıllı telefonu kontrol etme sayısı, akıllı telefonla-internetle günlük ilgilenme saati ve kendilerini akıllı telefon bağımlısı olarak değerlendirme durumuna yönelik sorular yer aldı.

\section{Akılı Telefon Bağımıılığı Ölçeği-Kısa Formu (ATBÖ-KF)}

Akıllı telefon bağımlılığı riskini ölçmek için Kwon ve arkadaşları (23) tarafından geliştirilen, 10 maddeden oluşan ve altılı likert dereceleme ile değerlendirilen bir ölçektir. Türkçe geçerlilik ve güvenirlik çalışması 2015 yılında Noyan ve arkadaşları (8) tarafından yapılmıştır. Ölçeğin maddeleri 1 'den 6'ya doğru puanlandırılmıştır. Ölçek puanları 10-60 arasında değişmektedir. Testten elde edilen puan arttıkça bağımlılık için riskin arttığı değerlendirilmektedir. Ölçek bir faktörlü olup alt ölçekleri yoktur (8).

\section{İnternet Bağımlılığı Ölçeği (İBÖ)}

$\mathrm{Bu}$ ölçek internet bağımlılığ 1 ve kullanım özelliklerini 
ölçmek için Günüç ve Kayri (7) tarafından 2010 yılında Türkçe olarak geliştirilmiş olup 35 maddeden oluşmaktadır. Ölçek beșli likert tipindedir ve ölçek maddeleri 5'ten 1'e doğru puanlandırılmıştır. Ölçekten elde edilen puanlar 35-175 arasında değişmektedir. Yüksek puanlar bağımlılık şiddetinin daha fazla olduğunu göstermektedir (7).

\section{Kol, Omuz ve El Sorunları Anketi (DASH)}

Kol, Omuz ve El Sorunları Anketi (DASH), Dünya Sağlık Örgütü (DSÖ) modeli temel alınarak American Academy of Orthopedic Surgeons (AAOS) tarafından geliştirilen, üst ekstremite fonksiyon durumlarını değerlendirmeye yarayan bir ankettir. Türkçe uyarlamasının güvenirliği ve geçerliğini 2006 yılında Düger ve arkadaşları (24) yapmıştır. Anket üç bölümden oluşmakta olup, ölçekte yer alan tüm sorularda kişi 5 puanlı (1: zorluk yok, 2: hafif derecede zorluk, 3: orta derecede zorluk, 4: aşırı zorluk, 5: hiç yapamama) likert sisteminde kendine uygun olan yanıtı işaretler. DASH anketi sonucuna göre; her bir bölümden 0-100 arasında bir sonuç elde edilir (0: hiç sorun yok, 100: maksimum sorun).

Araştırmacı tarafından öğrencilere araştırma hakkında bilgi verildikten sonra, araştırmaya katılmayı kabul eden ögrencilere veri toplama formları dağıtılarak, burada yer alan soruları yanıtlamaları istendi. Yanıtlamaları için geçen süre en fazla 20 dakika olarak hesapland1.

Araştırma amacına uygun olarak toplanan verilerin istatistiksel analizi IBM SPSS 22.0 (SPSS Inc., Chicago, IL, USA) istatistik paket programı kullanılarak analiz edildi. Ölçeklerin toplam puan ortalamaları hesaplanmış olup, ölçek puanlarının normal dağılma uygunluğunu belirlemek için verilere normallik testi uyguland. $\mathrm{Bu}$ analize göre, ölçek puanlarının normal dağılım gösterdiği belirlendi ( $p>0,05)$. Verilerin istatistiksel analizi sayı, yüzde, ortalama \pm standart sapma ile Bağımsız grup t testi, Tek Yönlü Varyans Analizi (ANOVA), istatistiksel farklılığın bulunduğu durumlarda ikincil çoklu karşılaştırma testi (Tukey HSD Testi) ve Pearson Korelasyon analizi ile yapıldı.

Araștırma öncesinde ölçeklerin geçerlik ve güvenirliğini yapan sorumlu yazarlardan (her üç ölçek için) e-mail aracılığı ile ölçek kullanım izni alınmıştır. Araştırmanın yürütülebilmesi için etik (Karar No: 2016/10) ve yasal izinler alınmış, araştırmaya katılan öğrencilerden de sözel araştırmaya gönüllü katıldıklarına ilişkin yazılı ve sözel onam alınmıştır.

\section{Bulgular}

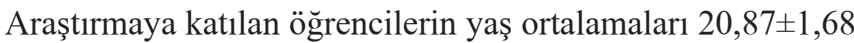
(min: 18, max: 29) olarak hesaplanmış olup, tanıtıcı özelliklerine ilişkin bulgular Tablo 1'de gösterilmiştir. Öğrencilerin \%42,6's1 günde 41 ve daha fazla kontrol ettiklerini, \%46's1 ak1llı telefon ve internetle günlük olarak 3-4 saat ilgilendiklerini, \%49,5'i bağımlı olabildiklerini ifade etmişlerdir (Tablo 1).

Araştırmaya dahil öğrencilerin ATBÖ-KF ortalama toplam puan1 23,31 $\pm 10,20$ (min: 10, max: 53), İBÖ ortalama toplam puan1 73,62 $\pm 22,68$ (min: 5, max: 160), DASH ortalama toplam puanı 42,97 $\pm 12,18$ (min: 30, max: 100) olarak belirlenmiştir.
Araştırma verilerini toplamak amacıyla kullanılan ATBÖKF, İBÖ ve DASH arasındaki doğrusal ilişkilerin önemlilik durumu Tablo 2'de verilmiştir. Yapılan istatistiksel analiz sonucunda; ATBÖ-KF ile İBÖ ve DASH arasında pozitif yönde anlamlı bir ilişki saptanmıştır $(\mathrm{p}<0,01)$.

Tablo 1. Öğrencilerin Tanıtıcı Özelliklerinin Dağılımı.

\begin{tabular}{|c|c|c|}
\hline Tanıtıcı Özellikler & $\mathbf{N}$ & $\%$ \\
\hline \multicolumn{3}{|l|}{ Yaş Grubu } \\
\hline 18-23 yaş & 253 & 87.5 \\
\hline $24-29$ yaş & 36 & 12.5 \\
\hline \multicolumn{3}{|l|}{ Cinsiyet } \\
\hline $\mathrm{K}_{1 \mathrm{Z}}$ & 225 & 77.9 \\
\hline Erkek & 64 & 22.1 \\
\hline \multicolumn{3}{|l|}{ Sınıf Düzeyi } \\
\hline Birinci sinif & 67 & 23.1 \\
\hline İkinci sınıf & 63 & 21.8 \\
\hline Üçüncü sınıf & 82 & 28.4 \\
\hline Dördüncü sınıf & 77 & 26.6 \\
\hline \multicolumn{3}{|l|}{ Kalınan yer } \\
\hline Ailemle birlikte & 85 & 29.4 \\
\hline Yurtta & 130 & 45.0 \\
\hline Evde arkadaşlarımla & 66 & 22.8 \\
\hline Evde tek başıma & 8 & 2.8 \\
\hline \multicolumn{3}{|c|}{$\begin{array}{l}\text { Akıllı telefonu günlük kontrol etme } \\
\text { sayısı }\end{array}$} \\
\hline 10 dan az & 14 & 4.8 \\
\hline $10-20$ defa & 39 & 13.5 \\
\hline $21-30$ defa & 51 & 17.6 \\
\hline $31-40$ defa & 62 & 21.5 \\
\hline 41 ve daha fazla & 123 & 42.6 \\
\hline \multicolumn{3}{|c|}{$\begin{array}{l}\text { Akıllı telefon ve internetle günlük } \\
\text { ilgilenme saati }\end{array}$} \\
\hline 1 saatten az & 8 & 2.8 \\
\hline $1-2$ saat & 72 & 24.9 \\
\hline $3-4$ saat & 133 & 46.0 \\
\hline 5 saat ve üzeri & 76 & 26.3 \\
\hline \multicolumn{3}{|c|}{$\begin{array}{l}\text { Kendinizi bağımlı olarak } \\
\text { değerlendirme durumunuz }\end{array}$} \\
\hline Bağımlı değilim & 74 & 25.6 \\
\hline Fikrim yok & 30 & 10.4 \\
\hline Belki bağımlıyım & 143 & 49.5 \\
\hline Kesin Bağımlıyım & 42 & 14.5 \\
\hline TOPLAM & 289 & 100 \\
\hline
\end{tabular}

$\mathrm{Bu}$ çalışmada; öğrencilerin cinsiyet ve kaldıkları yer değişkenleri bakımından öğrencilerin üst ekstremite fonksiyonel aktivite düzeyleri (DASH) toplam puan ortalamaları farklı bulunmuştur $(\mathrm{P}<0.001)$, öğrencilerin sınıf düzeyi, ak1llı telefonu günlük kontrol etme sayısı, akıllı telefon, internetle günlük ilgilenme süresi ve kendini bağımlı olarak değerlendirme durumlarına göre akıllı telefon bağımlılığ 1 ve internet bağımlılığı toplam puan ortalama farkları istatistiksel olarak anlamlı düzeyde bulundu $(\mathrm{p}<0,05$, Tablo 3$)$. İkiden fazla ortalamanın karşılaştırıldığı değişkenlerin hangi seviyelerinde farklılığın olduğunu belirlemek için yapılan çoklu karşılaştırma testi sonuca göre ATBÖ-KF ve İBÖ' 
de 1. ve 2. sinıf toplam puan ortalamaları arasında önemli farklilık bulunmazken $(P>0,05) 3$. ve 4 . sinif ortalamaları bunlardan önemli derecede düşük bulunmuştur $(\mathrm{P}<0,05)$. DASH toplam puan ortalaması bakımından evde tek başına ve evde arkadaşları ile birlikte kalanların ortalamaları farklı olmayıp aile ve yurtta kalanlardan istatistiksel olarak önemli derecede daha düşük ortalamaya sahip oldukları gözlenmiştir $(\mathrm{P}<0,05)$. Ak1ll telefonu 10 dan az ve 10-20 defa kontrol edenlerin ATBÖ-KF toplam puan ortalaması daha çok kontrol edenlerden önemli derecede az bulunmuştur $(\mathrm{P}<0,05)$. İBÖ toplam puan ortalaması 41 ve daha fazla kontrol edenlerde en yüksek bulunurken 31-40 defa kontrol edenlere göre farklı bulunmamıştır $(P>0,05)$. Akıllı telefon ve internetle günlük ilgilenme saati 3 saat ve daha fazla olanların hem ATBÖ-KF hem de İBÖ toplam puan ortalamaları daha az kullananlardan yüksek bulunmuştur $(\mathrm{P}<0,05)$. Kendini bağımlı olarak değerlendirmeyen ve fikrim yok diyenlerin ATBÖ-KF ve İÖ toplam puan ortalamaları belki ve kesin bağımlıyım diyenlerden önemli derecede daha düşük bulunmuştur $(\mathrm{P}<0,05)$ (Tablo 3).

\begin{tabular}{lcc}
\hline \multicolumn{3}{l}{ Tablo 2. Ölçeklerin birbirleriyle korelasyonları } \\
\hline Ölçekler & ATBÖ-KF & İBÖ \\
\hline \multirow{2}{*}{ İBÖ } & $\mathrm{r}=0.637$ & \\
& $\mathrm{p}=0.000$ & \\
\hline \multirow{2}{*}{ DASH } & $\mathrm{r}=0.175$ & $\mathrm{r}=0.213$ \\
& $\mathrm{p}=0.003$ & $\mathrm{p}=0.000$
\end{tabular}

r:Pearson korelasyon analizi

ATBÖ-KF; Akıllı Telefon Bağımlılı̆̆ı Ölçeği-Kısa Formu

İBÖ; İnternet Bağımlılığı Ölçeği

DASH; Kol, Omuz ve El Sorunları Anketi

\section{Tartışma}

Hemşirelik öğrencilerinde akıllı telefon ve internet bağımlılığı ile üst ekstremite fonksiyonel aktivite düzeyleri arasındaki ilişkinin incelenmesi amacıyla yapılan bu çalışma sonucunda; öğrencilerin ATBÖ-KF ortalama toplam puanı $23,31 \pm 10,20$, İBÖ ortalama toplam puanı $73,62 \pm 22,68$, DASH ortalama toplam puan1 $42,97 \pm 12,18$ olarak belirlenmiştir. Elde edilen bu puanlardan öğrencilerin düşük düzeyde akıllı telefon ve internet bağımlısı olduğu ve düşük düzeyde üst ekstremite fonksiyon aktivitelerinde sorun yaşadıkları bulunmuştur. Ülkemizde Kırağ ve arkadaşlarının (18) hemşirelik öğrencileri üzerinde yapmış oldukları bir çalışma sonucunda, öğrencilerin düşük düzeyde internet bağımlısı olduğu saptanmıştır. Noyan ve arkadaşlarının (8) yaptıkları çalışmada üniversite öğrencilerinin düşük düzeyde akıllı telefon bağımlısı olduğu belirlenmiştir.
Tablo 3. Öğrencilerin tanıtıcı özelliklerine göre ATBÖ-KF, İBÖ ve DASH toplam puan ortalamalarının karşılaştııılması $(\mathrm{N}=289)$

\begin{tabular}{|c|c|c|c|c|}
\hline $\begin{array}{l}\text { Tanıtıcı } \\
\text { Özellikleri }\end{array}$ & $\mathbf{N}$ & $\begin{array}{c}\text { ATBÖ-KF } \\
\text { Toplam } \\
\text { Puanı }\end{array}$ & $\begin{array}{c}\text { İBÖ } \\
\text { Toplam } \\
\text { Puanı }\end{array}$ & $\begin{array}{c}\text { DASH } \\
\text { Toplam } \\
\text { Puanı }\end{array}$ \\
\hline \multicolumn{5}{|l|}{ Yaş Grubu } \\
\hline $18-23$ yaş & 253 & $23.54 \pm 10.4$ & $74.09 \pm 22.7$ & $43.41 \pm 12.4$ \\
\hline \multirow[t]{2}{*}{$24-29$ yaş } & 36 & $21.75 \pm 8.43$ & $70.36 \pm 22.5$ & $39.83 \pm 10.1$ \\
\hline & & 0.325 & 0.356 & 0.099 \\
\hline \multicolumn{5}{|l|}{ Cinsiyet } \\
\hline $\mathrm{K}_{1 \mathrm{Z}}$ & 255 & $23.32 \pm 10.2$ & $73.62 \pm 22.0$ & $44.35 \pm 12.2$ \\
\hline \multirow[t]{2}{*}{ Erkek } & 64 & $23.29 \pm 10.1$ & $73.65 \pm 25.1$ & $38.12 \pm 10.6$ \\
\hline & & 0.985 & 0,992 & 0.000 \\
\hline \multicolumn{5}{|l|}{ Sınıf Düzeyi } \\
\hline $\begin{array}{l}\text { Birinci sınıf } \\
\text { İkinci sınıf } \\
\text { Üccüncü sınıf } \\
\text { Dördüncü sınıf }\end{array}$ & & $\begin{array}{c}23.19 \pm 9.8 \\
26.42 \pm 10.8 \\
22.23 \pm 9.9 \\
22.03 \pm 9.7 \\
\end{array}$ & $\begin{array}{l}74.74 \pm 23.0 \\
81.47 \pm 28.3 \\
71.54 \pm 21.4 \\
68.45 \pm 16.0 \\
\end{array}$ & $\begin{array}{l}44.38 \pm 12.3 \\
44.17 \pm 13.8 \\
41.79 \pm 10.8 \\
42.01 \pm 11.9 \\
\end{array}$ \\
\hline & & 0.045 & 0.006 & 0.431 \\
\hline \multicolumn{5}{|l|}{ Kalınan yer } \\
\hline $\begin{array}{l}\text { Ailemle birlikte } \\
\text { Yurtta } \\
\text { Evde } \\
\text { arkadaşlarımla } \\
\text { Evde tek başıma }\end{array}$ & & $\begin{array}{l}23.95 \pm 10.0 \\
23.55 \pm 10.6 \\
22.22 \pm 9.32 \\
21.75 \pm 12.4\end{array}$ & $\begin{array}{l}72.81 \pm 22.4 \\
76.58 \pm 23.0 \\
70.28 \pm 21.5 \\
61.87 \pm 24.9\end{array}$ & $\begin{array}{c}44.64 \pm 12.5 \\
44.56 \pm 12.8 \\
38.51 \pm 9.3 \\
36.0 \pm 4.5\end{array}$ \\
\hline & & 0.721 & 0.116 & 0.001 \\
\hline
\end{tabular}

\begin{tabular}{lcccc}
\hline $\begin{array}{l}\text { Akıllı telefonu } \\
\text { günlük kontrol } \\
\text { etme sayısı }\end{array}$ & & & & \\
\cline { 1 - 1 } 10 dan az & & $14.64 \pm 4.9$ & $58.92 \pm 19.7$ & $39.00 \pm 7.4$ \\
$10-20$ defa & & $18.69 \pm 6.7$ & $64.07 \pm 18.1$ & $43.61 \pm 11.9$ \\
$21-30$ defa & & $19.35 \pm 6.89$ & $67.76 \pm 19.6$ & $39.92 \pm 11.0$ \\
$31-40$ defa & & $24.03 \pm 10.3$ & $73.43 \pm 22.9$ & $43.06 \pm 12.6$ \\
41 ve daha fazla & & $27.05 \pm 10.9$ & $80.86 \pm 22.9$ & $44.43 \pm 12.7$ \\
\hline & $\mathbf{P}$ & $\mathbf{0 . 0 0 0}$ & $\mathbf{0 . 0 0 0}$ & 0.159 \\
\hline
\end{tabular}

\begin{tabular}{|c|c|c|c|}
\hline $\begin{array}{l}\text { Akılı telefon ve } \\
\text { internetle günlük } \\
\text { ilgilenme saati }\end{array}$ & \multirow[b]{2}{*}{$13.62 \pm 3.6$} & \multirow[b]{2}{*}{$69.37 \pm 19.2$} & \multirow[b]{2}{*}{$38.0 \pm 6.4$} \\
\hline 1 saatten az & & & \\
\hline $1-2$ saat & $19.93 \pm 7.8$ & $65.44 \pm 20.3$ & $41.11 \pm 11.0$ \\
\hline 3-4 saat & $22.82 \pm 9.9$ & $73.30 \pm 21.3$ & $44.57 \pm 13.1$ \\
\hline 5 saat ve üzeri & $28.40 \pm 10.9$ & $82.40 \pm 24.5$ & $42.46 \pm 11.7$ \\
\hline $\mathbf{P}$ & 0.000 & 0.000 & 1.142 \\
\hline \multicolumn{4}{|l|}{$\begin{array}{l}\text { Kendinizi } \\
\text { bağımlı olarak } \\
\text { değerlendirme } \\
\text { durumunuz } \\
\end{array}$} \\
\hline Bağımlı değilim & $17.89 \pm 6.6$ & $63.52 \pm 21.5$ & $41.29 \pm 11.9$ \\
\hline Fikrim yok & $20.13 \pm 7.0$ & $66.00 \pm 13.4$ & $44.90 \pm 13.8$ \\
\hline Belki bağımlıyım & $23.99 \pm 9.6$ & $74.00 \pm 18.3$ & $43.11 \pm 10.8$ \\
\hline Kesin Bağımlıyım & $32.85 \pm 11.8$ & $95.61 \pm 27.8$ & $44.04 \pm 15.4$ \\
\hline $\mathbf{P}$ & 0.000 & 0.000 & 0.478 \\
\hline
\end{tabular}

P: Varyans analizi önem düzeyi;

a,b,c: Her bir özellik için aynı harfi taşıyan grup ortalamaları farklı değildir $(\mathrm{P}>0,05)$. ATBÖ-KF; Akıllı Telefon Bağımlılı̆ı Ölçeği-Kısa Formu

İBÖ; İnternet Bağımlılı̆̆ı Ölçeği

DASH; Kol, Omuz ve El Sorunları Ölçeği Anketi 
Konuyla ilgili yapılan benzer ulusal ve uluslararası çalışmalarda gençlerde akıllı telefon ve internet bağımlılık düzeyinin düşük olduğu bulunmuştur $(25,26)$. Bu bulgular bizim çalışma bulgularımızla benzerlik göstermektedir. $\mathrm{Bu}$ sonuçlar hemşirelik öğrencilerinde akıllı telefon ve internet bağımlılığının çok yaygın olmadığı şeklinde yorumlanmıştır. Diğer yandan öğrencilerin düşük düzeyde akıllı telefon ve internet bağımlısı olma durumları ile paralel olarak düşük düzeyde üst ekstremite fonksiyonel aktivite düzeylerinde sorun yaşadıkları tahmin edilmektedir.

Yapılan bu çalışma sonucunda; ATBÖ-KF ile İBÖ ve DASH arasında pozitif yönde anlamlı bir ilişki saptanmıştır (Tablo 2). Noyan ve arkadaşlarının (8) yaptığı çalışmada ATBÖ-KF ile İBÖ arasında istatistiksel olarak anlamlı pozitif korelasyon saptanmıştır. Aynı şekilde Demirci ve arkadaşlarının (27) üniversite öğrencileri ile yaptıkları çalışmada da ATBÖKF ile İBÖ arasında pozitif bir ilişki bulunmuştur. Çalışma sonucumuz bu çalışma bulgularıyla uyumludur. Akı1lı telefon ve internet kullanımı kişilerin sağlığını bozarak birçok olumsuz sonuca yol açtığ 1 bildirilmektedir $(8,11,12)$. Özellikle de genel işlevsellik üzerine etki ederek fiziksel sağlığı kötü etkilediği belirtilmektedir $(9,15)$. Bu bilgilerden yola çıkarak DASH ile ATBÖ-KF ve İBÖ arasında bir ilișki bulunması, akıllı telefon ve internet bağımlılığının kişilerin üst ekstremite fonksiyonlarını etkileyebilme olasılığına bağlı olarak geliştiği düşünülmüştür.

Öğrencilerin kaldıkları yer ve cinsiyet faktörü ile DASH arasında anlamlı bir fark bulunmuş olup ailesiyle birlikte kalan öğrencilerin evde tek başına yaşayan öğrencilere göre, k1z öğrencilerin erkek öğrencilere göre DASH toplam puanlarının daha yüksek olduğu saptanmıștır (Tablo 3). Konuyla ilgili benzer bir çalışmaya rastlanılmamış olup, bu bulguların öğrencilerin sosyokültürel ve vücut yapısı gibi faktörlerden kaynaklanabileceği tahmin edilmiştir.

Bu çalışmadan elde edilen sonuçlar doğrultusunda 2. sınıfta öğrenim gören, akıllı telefonu günlük 41 ve daha fazla kontrol eden, akıllı telefon ve internetle günlük ilgilenme saati 5 saat üzeri olan ve kendini kesin bağımlı olarak değerlendiren öğrencilerin diğer gruptaki öğrencilere oranla yüksek düzeyde akıllı telefon ve internet bağımlısı olduğu görülmüştür (Tablo 3). Noyan ve arkadaşlarının (8) çalışmasında akıllı telefonu günlük kontrol etme sayısı, günlük ilgilenme saati ve kendini bağımlı olarak değerlendirme gibi değişkenlerinin akıllı telefon bağımlılığı ve internet bağımlılığını etkilediği bulunmuştur. Demirci ve arkadaşlarının (27) ve Gökçearslan ve arkadaşlarının (11) çalışmalarında da günlük akıllı telefon kullanım sıklığı ile akıllı telefon bağımlılığı arasında bir ilişki bulunmuştur. Bunların dışında literatürdeki diğer benzer çalışmalarda internet kullanım sıklığı arttıkça internet bağımlılığı anlamlı düzeyde arttığı vurgulanmaktadır $(18,28)$. Çalışma sonuçlarımız literatürle benzerlik göstermektedir. Yukarıdaki çalışmalarda sınıf değişkeni ele alınmamış olup, bizim çalışmamızda ikinci sınıfların diğer sınıflara göre daha yüksek oranda akıllı telefon ve internet kullandığ 1 görülmüştür. $\mathrm{Bu}$ durumun ikinci sınıf öğrencilerinin ders yoğunluklarının diğer sinıflara göre daha fazla olmasından dolayı derslere yönelik araştırma amaçlı kullanabileceklerinden kaynaklanabileceği düşünülmüştür.

Çalışmada erkek ve kız öğrencilerin ATBÖ-KF ve İBÖ toplam puanlarının yaklaşık aynı olduğu bulunmuş ve cinsiyet faktörünün akıllı telefon ve internet bağımlılık düzeyini etkilemediği görülmüştür. Konuyla ilgili yapılan çalışmalarda da cinsiyet faktörünün akıllı telefon ve internet bağımlılığını etkilemediği saptanmıştır $(8,29)$. Ancak, cinsiyetler arasında akıllı telefon ve internet bağım $\neg$ lılığ 1 açısından fark olduğunu gösteren araştırmalarda bulunmaktadır. Kırağ ve arkadaşları (18) internet bağımlılığının erkek öğrencilerde daha yüksek olduğunu bulmuşlardır. Demirci ve arkadaşlarının (27) yaptıkları çalışmada ise kız öğrencilerin erkek öğrencilere göre daha yüksek oranda akıllı telefon bağımlısı olduğu belirlenmiştir. Yukarıdaki çalışmalardan farklı olarak, bu çalışmanın farklı sosyokültürel bölgede bulunan bir üniversitede yapılmış olması ve erkek katılımcı sayısının az olması akıllı telefon ve internet kullanımındaki cinsiyet farklılığını ortaya koyamamış olabileceği düşünülmüştür.

$\mathrm{Bu}$ araştırmanın bazı sınırlılıkları mevcuttur. Araştırma evrenine ulaşma yüzdesinin (\%60) düşük olması, araştırmanın tek bir merkezde yürütülmesi ve veri toplama formlarında yer alan soruların öğrencilerin ifadelerine dayalı olması araştırmanın sınırlılıklarını oluşturmaktadır. Gelecek araştırmalarda hem niteliksel hem de niceliksel desenlerde öğrencilerin akıllı telefon ve internet bağımlılı̆̆ ile üst ekstremite fonksiyonel aktivite düzeyleri arasındaki ilişkiyi incelemek için farklı yüksekokul ve fakültelerde daha geniş araştırma örneklemi ile farklı değişkenleri de dikkate alarak bu çalışmanın tekrarlanması önemlidir.

\section{Sonuç}

$\mathrm{Bu}$ çalışma sonucunda, hemşirelik bölümü öğrencilerinin düşük düzeyde akıllı cep telefonu ve internet bağımlısı olduğu belirlenmiştir. Ayrıca, öğrencilerin akıllı telefon ve internet bağımlılık düzeyleri ile üst ekstremite fonksiyonel aktivite düzeyleri arasında bir ilişki olduğu bulunmuştur. Gelecek araştırmalarda hem niteliksel hem de niceliksel desenlerde öğrencilerin akıllı telefon ve internet bağımlılığ1 ile üst ekstremite fonksiyonel aktivite düzeyleri arasındaki ilişkiyi incelemek için farklı yüksekokul ve fakültelerde daha geniş araştırma örneklemi ile cinsiyet faktörü de kontrol edilerek diğer değișkenleri dikkate alarak bu çalışmanın tekrarlanması önemlidir. Ayrıca akıllı cep telefonu ve internet bağımlılı̆̆ının olumsuz etkilerine yönelik farkındalık oluşturmak için öğrencilere yönelik seminer, konferans ve seçmeli derslerin uygulamaya konulması önerilebilir.

\section{Kaynakça}

1. Egger O, Rauterberg M. Internet Behaviour and Addiction. Unpublished master's thesis, Work \& Organisational Psychology Unit (IfAP), Swiss Federal Institute of Technology (ETH). 1996 Zurih.

2. Griffiths MD. Internet addiction: fact or fiction?. The Psychologist 1999; 12: 246-50.

3. Kim S, Kim R. A study of internet addiction: status, causes, and remedies- focusing on the alienation factor. International 
Journal of Human Ecology 2002; 3(1): 1-19.

4. Günüç S. İnternet Bağımlılık Ölçeğinin Geliştirilmesi ve Bazı Demografik Değişkenler ile İnternet Bağımlılığı Arasındaki İlişkilerin İncelenmesi. Yüksek Lisans Tezi, Sosyal Bilimler Enstitüsü, Yüzüncü Yıl Üniversitesi, 2009, Van.

5. Lepp A, Li J, Barkley JE, Salehi-Esfahani S. Exploring the relationships between college students' cell phone use, personality and leisure. Computers in Human Behavior 2015; 43: 210-9.

6. Smith A. US smartphone use in 2015. Pew Research Center, 2015.

7. Günüç S, Kayri M. Türkiye'de internet bağımlılık profili ve internet bağımlılık ölçeğinin geliştirilmesi: geçerlik ve güvenirlik çalışması. Hacettepe Üniversitesi Eğitim Fakültesi Dergisi 2010; 39: 220-3.

8. Noyan CO, Darçın AE, Nurmedov S, Yılmaz O, Dilbaz N. Akıllı telefon bağımlılığı ölçeğinin kısa formunun üniversite öğrencilerinde Türkçe geçerlilik ve güvenilirlik çalışması. Anadolu Psikiyatri Dergisi 2015;16 (Özel say1.1): 73-81.

9. Samaha M, Hawi NS. Relationships among smartphone addiction, stress, academic performance, and satisfaction with life. Computers in Human Behavior 2016; 57: 321-5.

10. Augner C, Hacker GW. Associations between problematic mobile phone use and psychological parameters in young adults. International Journal of Public Health 2012; 57(2): 437-41.

11. Gökçearslan Ş, Mumcu FK, Haşlaman T, Çevik YD. Modelling smartphone addiction: the role of smartphone usage, selfregulation, general self-efficacy and cyberloafing in university students. Computers in Human Behavior 2016; 63: 639-49.

12. Park N, Lee H. Social implications of smartphone use: Korean college students' smartphone use and psychological well-being. Cyberpsychology, Behavior, and Social Networking 2012; 15(9): 491-7.

13. Bian M, Leung L. Linking loneliness, shyness, smartphone addiction symptoms, and patterns of smartphone use to social capital. Social Science Computer Review 2015; 33(1): 61-79.

14. Orleans M, Laney MC. Children's computer use in the home: isolation or sociation. Social Science Computer Review 2000; 18(1): 56-72.

15. Thomee S, Harenstam A, Hagberg M. Mobile phone use and stress, sleep disturbances, and symptoms of depression among young adults-a prospective cohort study. BMC Public Health 2011; 11: 1-11.

16. Akın A, İskender M. Internet addiction and depression, anxiety and stres. International Online Journal of Educational
Sciences 2011; 3(1): 138-48.

17. Jang KS, Hwang SY, Choi JY. Internet addiction and psychiatric symptoms among Korean adolescents. The Journal of School Health 2008; 78(3): 165-71.

18. Kıră̆ N, Yıldız H, Hayar E, Güdü G, Kandemir E, Çınar H, Öztürk N. Hemşirelik öğrencilerinin internet bağımlılığı ve ilişkili faktörler. Uluslararası Hakemli Hemşirelik Araştırmaları Dergisi 2016; 8: 15-36.

19. Kim K, Ryu E, Chon MY. Internet addiction in Korean adolescents and its relation to depression and suicidal ideation: A questionnaire survey. International Journal of Nursing Studies 2006; 43(2): 185-92.

20. Spada MM, Langston B, Nikcevic AV. The role of metacognitions in problematic internet use. Computers in Human Behavior 2008; 24(5): 2325-35.

21. Yen JY, Yen CF, Chen CC. Family factors of internet addiction and substance use experience in Taiwanese adolescents. Cyberpsychology \& Behavior 2007; 10(3): 3239.

22. Tuncer ÖB, Genç H, Nacır B, Erdem HR. Determining risk factors in cumulative trauma disorders of computer users and effects of risk factors on disability. Turk J Phys Med Rehab 2015; 61: 298-306.

23. Kwon M, Lee JY, Won WY, Park JW, Min JA, Hahn C et al. Development and validation of a smartphone addiction Scale (SAS). PLoS ONE 2013; 8(2): e56936.

24. Düger T, Yakut E, Öksüz Ç, ve ark. Kol, omuz, ve el sorunları (disabilities of the arm, shoulder and hand-DASH) anketi Türkçe uyarlanmasının güvenirliği ve geçerliği. Fizyoterapi Rehabilitasyon 2006; 17(3): 99-107.

25. Johansson A, Götestam KG. Internet addiction: characteristics of a questionnaire and prevalence in Norwegian youth (12-18 years). Scandinavian Journal of Psychology 2004; 45(3): 223-9.

26. Akdağ M, Yılmaz BŞ, Özhan U, Şan İ. Üniversite öğrencilerinin internet bağımlılıklarının çeşitli değişkenler açısından incelenmesi. İnönü Üniversitesi Eğitim Fakültesi Dergisi 2014; 15(1): 73-96.

27. Demirci K, Orhan H, Demirdas A, Akpınar A, Sert H. Validity and reliability of the Turkish version of the smartphone addiction scale in a younger population. Bulletin of Clinical Psychopharmacology 2014; 24(3): 226-34.

28. Weinstein A, Lejoyeux M. Internet addiction or excessive internet use. The American Journal of Drug and Alcohol Abuse 2010; 36(5): 277-83.

29. Ergin A, Uzun SU, Bozkurt Aİ. T1p fakültesi öğrencilerinde internet bağımlılığı sıklığı ve etkileyen faktörler. Pamukkale T1p Dergisi 2011; 6(3): 134-42. 